\title{
A FESTA DA GEOGRAFIA, 2007-2010
}

Diogo Abreu ${ }^{1}$

SÉrgio Claudino ${ }^{2}$

A Festa da Geografia, que decorreu entre 2007 e 2010, tem pretendido a promoção da Geografia junto da sociedade civil, conjugando a divulgação e a reflexão com o debate e a convivialidade, ao encontro do espírito da ciência geográfica centrada na espacialidade dos quotidianos das comunidades.

A Festa da Geografia tem-se realizado em Mirandela, terra de Luciano Cordeiro (1844-1900), cuja estátua nos saúda à entrada da cidade. Figura proeminente do seu tempo, foi um dos fundadores da Sociedade de Geografia de Lisboa (1875) e seu Secretário Perpétuo. Integrou a representação de Portugal no Congresso de Geografia Colonial (1876) e na Conferência de Berlim (1884).

Procurando organizar um evento cultural marcante e assumindo a ligação à Geografia, através da figura de Luciano Cordeiro, a Câmara Municipal de Mirandela desafiou o Centro de Estudos Geográficos da Universidade de Lisboa (CEGUL) a promover a organização científica da Festa da Geografia. Esta iniciativa inspira-se na de outras Festas da Geografia, em particular na de Saint Dié-des-Vosges, em França, que ocorre desde 1990, e que conta com o patrocínio da União Geográfica Internacional. Aquele foi um convite honroso e irrecusável para o CEGUL, enquanto principal instituição portuguesa de investigação em Geografia.

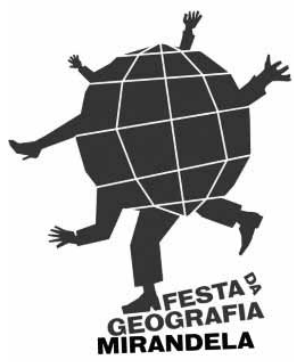

Fig. 1 - Logotipo da Festa da Geografia.

Fig. 1 - Logo of Geography Party.

1 Director do Centro de Estudos Geográficos da Universidade de Lisboa.

E-mail: diogo.abreu@ceg.ul.pt

2 Centro de Estudos Geográficos da Universidade de Lisboa. E-mail: sergio@campus.ul.pt 
Em 2007, a primeira Festa da Geografia decorreu no período de férias escolares e ao longo de mais de uma semana, de 14 a 22 de Julho de 2007. Numa região fronteiriça, a Festa teve por tema Península Ibérica: Território, Sociedade e Cidadania, sendo Espanha o país convidado. O convidado de honra foi o Professor Antoinne Bailly, professor catedrático jubilado da Universidade de Genebra, responsável pela Festa da Geografia de Saint Dié-des-Vosges durante muitos anos e desde 2010 presidente desse evento.

Da finalidade da Festa fala-nos, desde logo, o respectivo logotipo: um planeta humanizado e vivo, sugerido pela esfera terrestre de onde de destacam os membros de gente comum. O Manifesto, que então foi lançado, sintetiza o espírito e os objectivos desta iniciativa:

Geógrafos portugueses e espanhóis, professores e alunos de Geografia, planeadores, urbanistas, paisagistas, cientistas naturais e sociais, simples cidadãos, todos interessados no território e nos seus problemas, irão encontrar-se em Mirandela, para tratar de Geografia, apresentar os resultados dos seus trabalhos, ensinar e aprender, trocar conhecimentos e experiências, fortalecer laços de amizade, procurar descobrir novas realidades e discutir soluções dos novos e velhos problemas que nos afectam enquanto indivíduos.

Num ambiente de festa e de alegria, em que se juntam os jovens e os menos jovens, os especialistas e as pessoas comuns, irá acontecer em Mirandela a saudável troca de experiências, aspirações e novas descobertas dos nossos e dos outros territórios.

A primeira Festa da Geografia contou com uma extensa Comissão de Honra, encimada pelo Secretário de Estado do Ordenamento do Território e das Cidades, Professor Doutor João Ferrão - geógrafo e investigador do Centro de Estudos Geográficos durante muitos anos. A Comissão Científica integrou diversos investigadores do CEGUL e, ainda, elementos de cada um dos departamentos de Geografia das universidades públicas portuguesas. A Comissão Executiva reuniu elementos do CEGUL e da Câmara Municipal de Mirandela; nas edições seguintes, repetiu-se a presença de elementos destas entidades e, ainda, das associações sócio-profissionais de geógrafos. Numa prática que se repetiu nos anos seguintes, a Câmara Municipal de Mirandela facilitou o alojamento de jovens estudantes em instalações municipais.

Esta primeira Festa teve o programa mais ousado. Foi homenageada a figura de Luciano Cordeiro, lançou-se um livro de fotografias sobre Portugal, efectuou-se uma mostra de produtos regionais, realizaram-se exposições científicas, organizaram-se diversas mesas-redondas e debates, com a participação não só de geógrafos como de especialistas de muitas outras áreas, que assim se pretenderam mobilizar, e organizou-se um encontro científico, particularmente direccionado para estudantes de Mestrado e Doutoramento. Durante um dia, decorreram as Grandes Conferências sobre A Diversidade da Geografia, com conceituados especialistas portugueses e espanhóis. Promoveram-se ainda concursos escolares para os vários ciclos do ensino básico e secundário, de âmbito regional e nacional e, também, para o ensino superior (neste caso, também de fotografias), com conceituados especialistas portugueses e espanhóis; o presidente da Associação de Geógrafos Espanhóis apresentou o Manifesto de la Nueva Cultura del Território. Aproveitando este momento de encontro de geógrafos, reuniu a Comissão Nacional de Geografia. Porque de uma festa se tratava, houve espectáculos musicais, um deles sobre "paisagens sonoras" e animação de rua - com as vias centrais de Mirandela decoradas com estandartes alusivos à Festa da Geografia.

Podemos, entretanto, identificar dois aspectos menos conseguidos do evento: para além dos alunos de Geografia da Universidade de Lisboa, a Festa da Geografia teve dificuldade em atrair outros públicos, tendo a mobilização da população local ficado aquém das expectativas. 
Em 2008, indo ao encontro da vontade manifestada pela Câmara Municipal de Mirandela, a Festa da Geografia decorreu de 21 a 24 de Maio e teve por tema A Água. Visando a economia e a optimização de recursos, diminuiu-se a duração do evento e associou-se a festa ao feriado municipal (25 de Maio) e à Reginorde, feira municipal e regional que se realiza anualmente. Na Reginorde foi criado o Pavilhão da Geografia, onde em vários stands, se efectuaram exposições e diversos eventos, com destaque para o Salão de Geomática e SIG. No entanto, as principais actividades científicas, como as Grandes Conferências, continuaram a decorrer no Auditório Municipal. Não se repetiram os concursos, tendo-se desenvolvido a iniciativa $A$ Geografia vai às Escolas - diversos membros do CEGUL deslocaram-se a instituições locais do ensino básico e superior, enfatizando o interesse da Geografia na sociedade actual. Esta segunda edição contou com a presença do professor Giulliano Belleza, responsável da UGI pela organização das Festas da Geografia, tendo sido assinada a Declaração de Intenções de Mirandela, o primeiro documento da rede de Festivais de Geografia. Nesta edição desenvolveram-se diversas iniciativas relacionadas com a água (como o lançamento de livros, provas de água e Grandes Conferências). A inauguração do monumento à Geografia, numa das principais rotundas da cidade, foi um acontecimento particularmente marcante do ponto de vista simbólico e consolidou a associação da cidade de Mirandela à Geografia e à sua festa. Foi ainda atribuído o Prémio Luciano Cordeiro à Sociedade de Geografia de Lisboa. A Reginorde proporcionou o contacto com a Geografia de um maior número de populares, mas não se pode falar da popularização local desejada ou da mobilização de outros públicos para Mirandela. Por último, merece referência especial a visita em comboio ao vale do Tua, quando decorria uma acesa polémica em torno da construção de uma barragem hidroeléctrica no mesmo vale.

Em 2009, a Festa seguiu o figurino do ano anterior, tendo por tema $O$ Território, o Planeamento e o Poder Local. Foi inaugurada pelo Professor Doutor João Ferrão, membro do Governo ligado ao Ordenamento do Território, como já se referiu. O convidado de honra foi o Professor Vitorino Magalhães Godinho (que se fez representar, por motivos de saúde). As Grandes Conferências contaram com figuras de projeç̧ão mundial em Geografia (Antoine Bailly, Paul Claval, Bodo Freund e Horacio Capel) e assumiram, por isso, um destaque particular. Nesta Festa da Geografia participou um elevado número de alunos do Departamento de Geografia da Universidade de Lisboa, que aqui desenvolveram trabalho de campo.

A Festa desse ano terminou com uma reflexão sobre o futuro do evento. Por proposta do Presidente da Câmara Municipal de Mirandela, foi decidido constituir uma empresa responsável pela organização da Festa, de que seriam sócios a própria Câmara e outras câmaras municipais da região, bem como universidades e outras entidades relacionadas com a Geografia portuguesa. Sentiu-se, assim, uma reforçada vontade de co-responsabilizar o conjunto dos actores da Geografia portuguesa pela organização deste evento - assumido, até então, de forma quase exclusiva pela Câmara Municipal de Mirandela e pelo Centro de Estudos Geográficos da Universidade de Lisboa.

A Festa da Geografia de 2010 decorreu entre 21 e 23 de Maio; a Reginorde decorreu, neste ano, em Julho, pelo que a quase totalidade dos eventos se realizou no Auditório Municipal. Na sequência das diligências antes enunciadas, a organização coube à Associação Portuguesa de Geógrafos, sem prejuízo da colaboração activa das restantes entidades, desde logo o CEGUL. Esta festa teve por tema Territórios de Risco, temática com grande relevância regional e que merece uma atenção crescente às várias escalas. As personalidades convidadas foram o Professor Giuliano Bellleza e o Professor Antoine Bailly, cuja ligação a este evento data da primeira hora, tendo o último sido consagrado como seu patrono. A composição da 
Comissão de Honra e da Comissão Científica continuaram a reflectir uma participação diversificada de várias personalidades e instituições. A Comissão Executiva passou a contar, como era de esperar, com vários elementos da Associação Portuguesa de Geógrafos.

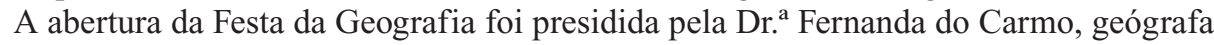
e Secretária de Estado do Ordenamento do Território e das Cidades - o que confirma a aceitação institucional deste evento. No momento em que deixou de liderar a organização científica desta inicativa, o Centro de Estudos Geográficos da Universidade de Lisboa homenageou a população de Mirandela, pelo seu contributo para este evento, através de uma lápide descerrada no primeiro dia do evento. Participaram muitos estudantes das várias universidades públicas com cursos de Geografia, a significar a sua consolidação entre os futuros geógrafos. À semelhança das edições anteriores, realizaram-se diversas mesas-redondas, conferências, um encontro de divulgação e debate entre estudantes e jovens investigadores de Geografia, apresentação de trabalhos audiovisuais de âmbito geográfico, exposições e visitas de estudo, para além de espectáculos musicais.

Na terra de Luciano Cordeiro, mas também no Portugal interior habitualmente esquecido, a Festa da Geografia constitui um desafio de mobilização do conjunto da sociedade portuguesa para a justa, harmoniosa e fraterna construção de um território de oportunidades para todos os cidadãos - objectivo último da ciência geográfica.

Em 2011, e também em consequência do período de contenção financeira vivido no país, a Câmara Municipal de Mirandela decidiu interromper a realização da Festa da Geografia. Quando se publicam estas linhas, a continuidade deste evento é, pois, incerta. Em qualquer caso, esta Festa tem constituído uma experiência de grande originalidade da Geografia portuguesa que, retomada ou não, está presente na memória dos geógrafos portugueses e os ajudará a inspirarem-se em futuras iniciativas de reflexão e divulgação da Geografia.

\title{
WORKSHOP BIOGEOGRAPHY, PHYLOGEOGRAPHY, AND THE INTERNATIONAL YEAR OF BIODIVERSITY 2010
}

\author{
Miguel Geraldes ${ }^{1}$ \\ CARLOS Neto ${ }^{2}$
}

No contexto do Ano Internacional da Biodiversidade, declarado pela Assembleia-Geral das Nações Unidas, foi organizado um workshop com o título Biogeography, Phylogeography, and the International Year of Biodiversity 2010. A molecular and genetic approach a 7 de Abril de 2010, Tratou-se de um evento internacional, realizado no Instituto de Geografia e

1 Bolseiro de Doutoramento da FCT, Centro de Estudos Geográficos da Universidade de Lisboa. E-mail: mgeraldes@campus.ul.pt

2 Professor do Departamento de Geografia do IGOT-UL. Investigador do Centro de Botânica Aplicada à Agricultura. E-mail: cneto@campus.ul.pt 